\title{
Regularly missed symptoms in primary and secondary narcolepsy
}

Carolina Diamandis ( $\nabla$ carolina.diamandis@europe.com )

LCG Greece https://orcid.org/0000-0002-6142-4195

Jacob S Adams

Clinical Neurologist

David Seideman

LCG Greece https://orcid.org/0000-0002-5749-5839

Marius Lazar

LCG Greece

Riku Honda

Biologist

\section{Research Article}

Keywords: narcolepsy, cataplexy, symptoms, cognitive function, sleep, seizures

Posted Date: May 20th, 2021

DOI: https://doi.org/10.21203/rs.3.rs-536627/v1

License: (c) (1) This work is licensed under a Creative Commons Attribution 4.0 International License. Read Full License 
Aulthorea

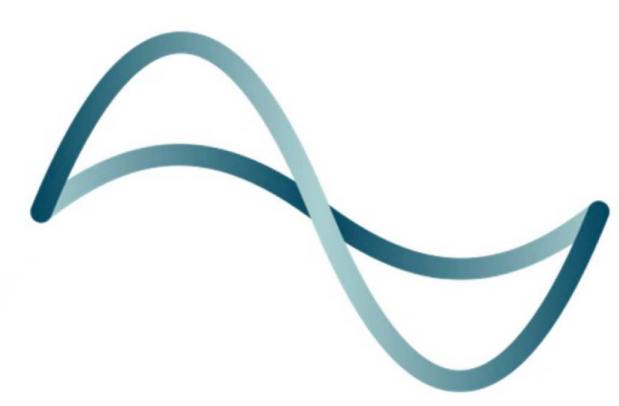

LAZAR RESEARCH"'

\section{Regularly missed symptoms in primary and secondary narcolepsy}

Jacob S Adams², Marius Lazar1, Riku Honda3, David Seideman1, Carolina Diamandis 1

\section{Affiliations}

1) Lazar Research Consortium

A non-profit entity

Established by Dr. Marius Lazar

2) Clinical Neurologist

South Africa and U.S.A.

3) Biologist

Tokyo, Japan

\section{Corresponding Author}

LCG Greece

Dr. Carolina Diamandis

Lazar Group Non-profit Research Consortium

Kifissias 16, Athina, 11526

Hellenic Republic

LazarClinicGroup@post.com 


\section{Abstract}

Based on an analysis of anonymized medical records from four hospitals in Asia and Africa, we succeeded in identifying symptoms typical for narcolepsy (with cataplexy) that are regularly overlooked because they are masked by the two severe leading symptoms. Our results do not differ between primary and secondary cases of narcolepsy.

\section{Introduction}

Narcolepsy is an illness of the brain, incurable and severely debilitating for most patients. Recent research shows that there is less hypocretin (also known as orexin) in the brains of narcolepsy patients than in healthy individuals, in both the primary and secondary forms (due to an underlying brain-organic disease). In narcolepsy patients, it is thought that an immune defect destroys the cells that produce the neurotransmitter hypocretin. Without hypocretin, humans cannot follow normal sleep and wake rhythms. Accordingly, in people with narcolepsy, the normal sleep-wake rhythm is disturbed and symptoms occur. ${ }^{15,16}$

Men and women are affected equally often. In the primary form, the first symptoms appear mainly between the ages of 15 and 30; the secondary form is independent of age and often more progressive. The most striking feature of narcolepsy is daytime sleepiness, which is manifested by attacks of falling asleep at any time of day and in the most unusual situations. In addition, there are spontaneous muscle relaxations, called cataplexy. Narcolepsy disease does not affect life expectancy, but leads to significant disabilities with considerable extent in terms of the limitations it causes. The quality of life of many sufferers significantly reduced. Narcolepsy is a purely organic disease. That is, it has a physical cause and is in no way psychological. 2,16

Patients increasingly lose the ability to resist imperative sleep attacks. Suddenly falling asleep is therefore not a sign of lack of interest, indifference or even laziness, but rather due to illness. As a rule, narcolepsy manifests itself through sleep attacks in monotonous situations in which concentration is easily reduced even in healthy people, for example when reading a long text, as a passenger in a car or while watching television. ${ }^{1,4-6}$

However, individuals suffering from narcolepsy not only fall asleep quickly during monotonous situations, but also suddenly and involuntarily in situations such as during meals or while driving a car on an empty road without much external stimulation. ${ }^{4-7}$ 
There is also the very dangerous (due to accidents) symptom of cataplexy which makes the patient's muscles fail, such as facial muscle slackening or a person's complete physical slump, often triggered by the biological correlates to emotions (catecholamine storm). Because the symptoms of cataplexy are very clear and a clear sign of the presence of narcolepsy, they greatly contribute to the diagnostic process. Nevertheless, the diagnosis is most often complicated or delayed because patients often perceive mild cataplexies as normal and assume that other people also experience brief moments of muscle failure. Accordingly, they do not tell their doctor that their jaw occasionally drops, for example. Still other sufferers do not talk about their symptoms for fear of suffering from a serious illness, such as a brain tumor. Fears of being mentally ill also cause patients not to see a neurologist. Because narcolepsy is a rare disease, doctors sometimes have quite some problems making the right diagnosis. It may be that the doctor himself has never seen or treated a narcolepsy patient before. If this is the case, the doctor may refer the affected person to a specialist in neurology or sleep medicine.10,12

\section{Well-known symptoms of narcolepsy with cataplexy}

The main symptom of narcolepsy is excessive daytime sleepiness, which occurs regardless of whether and how much the affected person has slept during the night. Other leading symptoms include cataplexy, disturbed nighttime sleep, hallucinations upon awakening from a seizure, and sleep paralysis. Thus, narcolepsy has not only one symptom, but is a symptom complex. The main symptom of narcolepsy is excessive daytime sleepiness, which is accompanied by involuntary falling asleep. It can be observed in almost all people suffering from narcolepsy. As a rule, the sleep attacks occur in the presence of low external stimulation (decrease in sympathetic nervous system activity). As long as the diagnosis of narcolepsy has not been made, those affected very often have to contend with prejudice, for example when they fall asleep at work or in the middle of a conversation. For those affected, staying awake is not a question of wanting to, they often simply cannot prevent falling asleep. Since outsiders often have no understanding, those affected withdraw and avoid activities with friends or family. People with narcolepsy are not only sometimes tired, but actually always and every day. A feeling like "really well rested" or "rested and fit" does not exist for people with narcolepsy. $9,10-12$

Cataplexies are short-lasting bouts of muscle failure that can vary in severity. In milder cases, for example, cataplexy causes only facial muscles to go slack. In other patients, however, the knees go weak, and in more severe cases, the patients may completely slump and fall to the floor, often resulting in injuries of 
various degree. This is also called a loss of muscle tone. During cataplexy, the patient remains fully conscious. Cataplexy is not dangerous in itself, but its consequences (injuries) are significant.2,10,11 Usually the attacks most often last only a few seconds. However, many cases are mild cataplexies, such as failure of the muscles of a finger or articulation difficulties. Cataplexies may occur several times a day in some patients and only a few times a year in others. ${ }^{1-6}$

About $80 \%$ of people with narcolepsy suffer from disturbed nighttime sleep. Compared to healthy people, night sleep is often not restful for people with narcolepsy. Sleep paralysis is a loss of muscle tone that occurs when falling asleep or waking up and is accompanied by a complete inability to move or paralysis. That is, one wakes up and cannot move. Sleep paralysis is not a definite sign of narcolepsy. They are seen in only $35 \%$ of patients with narcolepsy and also occur in $4 \%$ of the normal population. $1,8,10$

Hypnagogic (when falling asleep) or hypnopompic (when waking up) hallucinations are vivid, realistic and mostly fearful dream or delusion perceptions. The affected person sees and hears things when falling asleep or waking up, which do not take place in reality. The sensory phenomena experienced by a person suffering from narcolepsy during a hallucination are often unpleasant and sometimes bizarre or frightening. Hallucinations occur in about $50 \%$ of people with narcolepsy while waking up from an attack (seizure). ${ }^{1-7,12,14}$

\section{Method}

In addition to these commonly known symptoms, we suspected other symptoms specific to narcolepsy based on anecdotal reports. We therefore screened 127 anonymized patient records from a total of five Western-standard clinics (two in Africa, three in Asia) for evidence suggesting clustering of identical symptoms. Potentially confounding comorbidities were considered.

Of the 127 patients, 71 were male and 56 were female. The age range was 19 to 52 years, the mean age was 42 . Overall, $76 \%$ suffered from primary narcolepsy and $24 \%$ from secondary narcolepsy (with or without cataplexy). The data did not differ significantly between those with primary or secondary narcolepsy. The same is true for the sexes. 


\section{Results}

Symptom clusters beyond the known pathology:

$103 / 127(81 \%)$

Increase in wakefulness clinically and/or in EEG

between 21 and 03 hours (9:00 pm - 3:00 am)

$91 / 127(72 \%)$

Nocturnal hunger attacks:

$101 / 127(80 \%)$

Paralysis of digestive activity during sleep seizures:

109/127 (86\%)

Paralysis of digestive activity when sleep seizure is avoided by strong external stimulation:

$72 / 127(57 \%)$

Dream images or dreaming while awake

(analogous to a hallucination):

48/127 (38\%)

Occasional slurred speech as a symptom of cataplexy

of the vocal organs:

$89 / 127(70 \%)$

Occasional balance problems:

95/127 (75\%)

A feeling of being shattered after a sleep seizures:

112/127 (88\%)

Impairment of the olfactory sense (permanent):

$62 / 127(49 \%)$

Undesired weight gain:

119/127 (94\%)

Brain fog/cognitive challenges (more than one episode/day):

$126 / 127(99 \%)$

Mini-cataplexies (in max. one muscle segment such

as a finger) that results in injury:

98/127 (77\%)

Mini-cataplexies (in max. one muscle segment such

$127 / 127(100 \%)$ as a finger):

Diagnosed with "narcolepsy only" despite cataplectic symptoms: 49/129 (39\%)

Drop in measured intelligence (IQ) by more than

20 percentage points:

$27 / 59$

IQ data available from

59 patients only

Aversion to strong stimuli (bright light, crowds, etc)

$68 / 127(54 \%)$

Impairment of normal social interaction due to cognitive issues: $\quad$ 108/127 (85\%) 


\section{Discussion}

Obviously, the paucity of well-funded research has meant that relevant symptoms of narcolepsy (primary and secondary) have not been adequately researched and some misconceptions have persisted in medical textbooks for decades. Especially the supposed "refreshing" effect of a narcoleptic seizure seems more than questionable. The opposite appears to be the case. Aspects of cognitive decline, impairment of olfactory sense, and far-reaching dangers and hardships for people suffering from narcolepsy have also remained largely unnoticed. Our work shows the very clear tendency that narcolepsy is more than a sleeping disorder, but rather a complex neurological disease due to structural damage in the brain (cells and/or synapses). In particular, it is a highly significant finding that "narcolepsy without cataplexy" does not exist in our patients. Obviously, every narcolepsy is also accompanied by cataplexies, even if these are only minimally manifested. The risk of injury in people with narcolepsy has also apparently been completely underestimated up to now. Physicians worldwide are now also called upon to take a closer look at the concrete dangers to life and health of people with narcolepsy, as well as their social interaction issues, and to systematically investigate these risks.

\section{Conclusions}

We have succeeded in uncovering strong indications that the current description of narcolepsy in textbooks and other information publications is just as inadequate as the knowledge of most physicians who treat patients with narcolepsy. Now, a larger-scale study with a broader study design is urgently warranted.

\section{Limitations}

This study, like many others, has limitations. It is likely to be particularly relevant that patients were included only in the form of anonymized medical records. However, the records were from renowned and specialized clinics where meticulous documentation can be assumed. The number of patients was also relatively small, but cannot be considered underpowered given the rarity of this condition. Therefore, we believe that our results provide sufficiently robust results despite the previously mentioned and other limitations. 


\section{Conflicts of interest}

None.

\section{Ethical standards and patient's rights}

This study is based on the anonymized medical records of 127 fully informed adult patients who gave their written consent to such participation. Our paper is not reporting on a clinical trial, especially not a prospective one. Our research work is always conducted in accordance with the Declaration of Helsinki.

\section{References}

1. Bassetti, C.L.A., Adamantidis, A., Burdakov, D. et al.: Narcolepsy - clinical spectrum, aetiopathophysiology, diagnosis and treatment. Nat Rev Neurol 15, 519539 (2019), doi.org/ 10.1038/s41582-019-0226-9

2. Thorpy MJ. Cataplexy associated with narcolepsy: epidemiology, pathophysiology and management. CNS Drugs. 2006;20(1):43-50. doi: 10.2165/00023210-200620010-00004. PMID: 16396523.

3. Maia Palhano AC, Kim LJ, Moreira GA, Santos Coelho FM, Tufik S, Levy Andersen M. Narcolepsy, Precocious Puberty and Obesity in the Pediatric Population: a Literature Review. Pediatr Endocrinol Rev. 2018 Dec;16(2):266-274. doi: 10.17458/per.vol16.2018. Narcolepsypubertyobesity. PMID: 30556659.

4. Bassetti, C., Aldrich, M.: Narcolepsy. Neurol. Clin. 14, 545-571 (1996)

5. Han F. Sleepiness that cannot be overcome: narcolepsy and cataplexy. Respirology. 2012 Nov;17(8):1157-65. doi: 10.1111/j.1440-1843.2012.02178.x. PMID: 22471619.

6. Yoss, R., Daly, D. D.: Criteria for the diagnosis of the narcoleptic syndrome. Mayo Clin. Proc. 32, 320-328 (1957)

7. Lima FCB, do Nascimento Junior EB, Teixeira SS, Coelho FM, Oliveira GDP. Thinking outside the box: cataplexy without narcolepsy. Sleep Med. 2019 Sep;61:118-121. doi: 10.1016/j.sleep.2019.03.006. Epub 2019 Mar 20. PMID: 31427075. 
8. Ohayon, M., Priest, R. G., Zulley, J., Smirne, S., Paiva, T.: Prevalence of narcolepsy symptomatology and diagnosis in the European general population. Neurology 58, 1826-1833

9. Antelmi E, Pizza F, Franceschini C, Ferri R, Plazzi G. REM sleep behavior disorder in narcolepsy: A secondary form or an intrinsic feature? Sleep Med Rev. 2020 Apr;50:101254. doi: 10.1016/j.smrv.2019.101254. Epub 2019 Dec 19. PMID: 31931470.

10. Sullivan SS. Narcolepsy in adolescents. Adolesc Med State Art Rev. 2010 Dec;21(3):542-55, x-xi. PMID: 21302860.

11. Feldman NT. Narcolepsy. South Med J. 2003 Mar;96(3):277-82. doi:

10.1097/01.smj.0000056655.15660.42. PMID: 12659360.

12. Zhang J, Han F. Sleepiness in Narcolepsy. Sleep Med Clin. 2017 Sep;12(3):323-330. doi: 10.1016/j.jsmc.2017.03.008. Epub 2017 May 13. PMID: 28778231.

13. Mignot E, Black S. Narcolepsy risk and COVID-19. J Clin Sleep Med. 2020 Oct 15;16(10):1831-1833. doi: 10.5664/jcsm.8668. PMID: 32621581; PMCID: PMC7954017.

14. BaHammam AS, Alnakshabandi K, Pandi-Perumal SR. Neuropsychiatric Correlates of Narcolepsy. Curr Psychiatry Rep. 2020 Jun 5;22(8):36. doi: 10.1007/ s11920-020-01159-y. PMID: 32514698.

15. Mahoney CE, Cogswell A, Koralnik IJ, Scammell TE. The neurobiological basis of narcolepsy. Nat Rev Neurosci. 2019 Feb;20(2):83-93. doi: 10.1038/ s41583-018-0097-x. PMID: 30546103; PMCID: PMC6492289.

16. Bassetti CLA, Adamantidis A, Burdakov D, Han F, Gay S, Kallweit U, Khatami R, Koning F, Kornum BR, Lammers GJ, Liblau RS, Luppi PH, Mayer G, Pollmächer T, Sakurai T, Sallusto F, Scammell TE, Tafti M, Dauvilliers Y. Narcolepsy - clinical spectrum, aetiopathophysiology, diagnosis and treatment. Nat Rev Neurol. 2019 Sep;15(9):519-539. doi: 10.1038/s41582-019-0226-9. Epub 2019 Jul 19. PMID: 31324898. 